\title{
Cytotoxic T lymphocytes promote cytarabine-induced acute myeloid leukemia cell apoptosis via inhibiting Bcl-2 expression
}

\author{
RUI DENG ${ }^{*}$, FANG-YI FAN**, HAI YI, LI FU, YAN ZENG, YI WANG, \\ XIAO-JUAN MIAO, YAN-RONG SHUAI, GUANG-CUI HE and YI SU \\ Department of Hematology and Hematopoietic Stem Cell Transplantation, Chengdu Military \\ General Hospital of the People's Liberation Army, Chengdu, Sichuan 610083, P.R. China
}

Received April 14, 2016; Accepted March 17, 2017

DOI: $10.3892 /$ etm.2017.4620

\begin{abstract}
Acute myeloid leukemia (AML) remains difficult to cure due to its drug tolerance and refractoriness. Immunotherapy is a growing area of cancer research, which has been applied for the treatment of numerous types of cancer, including leukemia. The present study generated AML cell-specific cytotoxic T lymphocytes (CTLs) in vitro and investigated the effect of combining CTL treatment with one of the most commonly used drugs for the treatment of hematological malignancies, cytarabine, on AML cell apoptosis. Firstly, it was observed that monocyte-depleted peripheral blood lymphocytes from healthy donors could be used to generate large numbers of $\mathrm{CD}^{+} \mathrm{CD} 8^{+} \mathrm{CTLs}$ through immune stimulation. These $\mathrm{CD} 3^{+} \mathrm{CD} 8^{+} \mathrm{CTL}$ s could effectively recognize and induce the apoptosis of human Kasumi-3 AML cells. In addition, cytarabine-induced AML cell apoptosis was enhanced by CTL treatment. Western blotting revealed that Bcl-2 expression was downregulated in AML cells following cytarabine and CTL treatment, indicating that the synergistic effect of this treatment on AML cell apoptosis is due to the downregulation of Bcl-2. These results highlight the potential application of CTL immunotherapy for the treatment of AML. Further studies optimizing the specificity and potency of CTLs, and identifying favorable combinations with other chemotherapeutic drug are required.
\end{abstract}

Correspondence to: Dr Yi Su, Department of Hematology and Hematopoietic Stem Cell Transplantation, Chengdu Military General Hospital of the People's Liberation Army, 270 Rong Du Avenue, Chengdu, Sichuan 610083, P.R. China

E-mail: suhang1234@hotmail.com

\section{${ }^{*}$ Contributed equally}

Key words: cytotoxic T lymphocytes, acute myeloid leukemia cells, cytarabine, B-cell lymphoma 2, immunotherapy

\section{Introduction}

Acute myeloid leukemia (AML) remains difficult to cure because of its resistance to treatment. Although conventional chemotherapy induces initial remission in $\sim 60 \%$ of patients with AML and is the standard induction therapy for children and adults with AML, the majority of patients relapse after remission (1). The graft-versus-leukemia effects observed following hematopoietic stem cell transplantation (HSCT) in patients with AML indicate that inducing antitumor immunity would enable the eradication of AML and prevent relapse. However, because HSCT has high rates of treatment-associated mortality and morbidity, the indications for performing HSCT in the first remission remain controversial (2).

Immunotherapy, which has advanced rapidly in recent years, is a potent tool that has potential therapeutic applications in numerous cancer types (3). Immunotherapy enables the killing tumor cells through boosting a patient's endogenous immune responses, while not harming normal cells (3). This property gives immunotherapy an advantage compared with conventional chemotherapy or radiotherapy, which frequently have toxic side effects (3). Notably, numerous studies have investigated the use of immunotherapy for hematological malignancies (4-7). The present approaches for AML immunotherapy include antibody-based therapy, natural killer (NK) cell therapy and adoptive T cell immunotherapy. These techniques have demonstrated potential in preclinical applications, but require further testing. In addition, the underlying mechanisms of the cytotoxic effects of immunotherapy on tumor cells remain unclear.

Tumor antigen-T specific cells are almost always inefficient or suppressed in patients with cancer (8). In addition, chemotherapy and immunosuppressive cytokines secreted by tumor cells may suppress antitumor immunity in patients with cancer (9). Therefore, the adoptive transfer of tumor-specific $\mathrm{T}$ cells has been investigated in recent years $(10,11)$. Cytotoxic T lymphocytes (CTLs) exhibit more potent tumor cell-killing ability compared with NK cells, and may eradicate cancer stem cells, making CTL immunotherapy a promising cancer treatment with curative intent (12). Leukemia-derived CTL cell lines have been demonstrated to inhibit the proliferation of leukemic progenitor cells in vitro, which would enable the successful treatment of chronic myeloid leukemia in 
the accelerated phase (13). It has been demonstrated that adoptively-transferred $\mathrm{T}$ cell clones persist in vivo in response to low-dose interleukin-2 treatment, preferentially localize to tumor sites and mediate an antigen-specific immune response, which is characterized by the elimination of tumor-specific antigen-positive tumor cells (14).

Due the refractoriness and heterogeneity of cancer, multidisciplinary comprehensive treatment should be recommended in the first instance. However, how conventional cancer treatments and immunotherapies will affect one another remains unclear. Advances in tumor immunology have revealed key molecular mechanisms that represent the basis of therapeutic synergy or antagonism (15). For instance, previous studies have indicated that chemotherapy promoted tumor cells to be more susceptible to the cytotoxic effect of CTLs through a dramatic perforin-independent increase in permeability to GrzB released by the CTLs and this effect is mediated via upregulation of mannose-6-phosphate receptors on the surface of tumor cells $(16,17)$. Furthermore, some drugs of lower concentrations are able to upregulate the ability of dendritic cells (DCs) to present antigens to antigen-specific $\mathrm{T}$ cells and the stimulation of DC function has been associated with the upregulation of expression of antigen-processing machinery components and costimulatory molecules on DCs, which was interleukin (IL)-12-dependent and mediated by the autocrine or paracrine mechanisms (18). The present study aimed to investigate the effect of combined treatment with AML-specific CTLs and cytarabine (also known as Ara-C) on AML cell apoptosis. AML-specific CTLs exhibited the ability to recognize and kill tumor cells, which was enhanced through the addition of cytarabine. Furthermore, the results of the present study indicated that the cytotoxic effect of this combined treatment was attributable to the suppression of B-cell lymphoma 2 (Bcl-2) expression.

\section{Materials and methods}

Cell lines and reagents. The human AML cell line Kasumi-3 [cluster of differentiation (CD) $33^{+}$] was purchased from the American Type Culture Collection (Manassas, VA, USA). The Kasumi-3 cells were cultured in RPMI-1640 medium supplemented with 20\% fetal bovine serum (FBS) (both Sigma-Aldrich; Merck KGaA, Darmstadt, Germany) in an incubator at $37^{\circ} \mathrm{C}$ with $5 \% \mathrm{CO}_{2}$. Monocyte-depleted peripheral blood lymphocytes (PBLs) were cultured in immune cell-specialized culture medium (GT-T551 medium (TAKARA Biotechnology Co., Ltd., Dalian, China) in an incubator at $37^{\circ} \mathrm{C}$ with $5 \% \mathrm{CO}_{2}$. Ficoll lymphocyte separation liquid was purchased from GE Healthcare Life Sciences (Shanghai, China). Antibodies for flow cytometry analysis were purchased from BD Biosciences (Franklin Lakes, NJ, USA).

AML-CTL culture and characterization. A total of 3 males (age, 22-56 years old) and 2 females (age, 30-48 years old) healthy donors were recruited. The healthy volunteers gave their written informed consent and donated their blood for the present study. PBLs from healthy donors were separated and collected using density gradient centrifugation, according to the instruction book of the Ficoll (19), in the month of May 2015 at the Hematology Department, Cheng Du Military

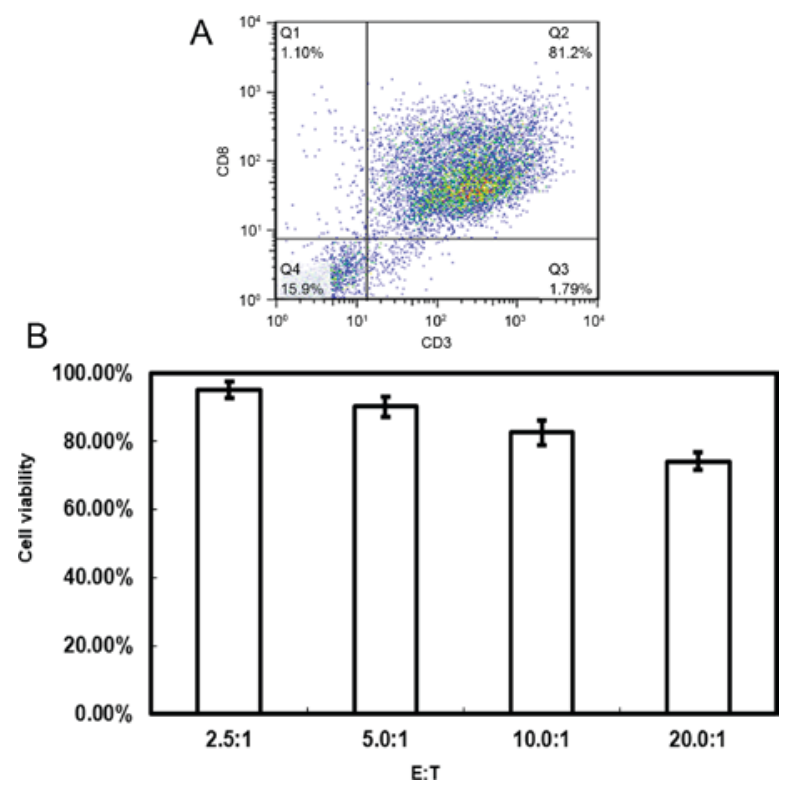

Figure 1. Generation and characterization of acute myeloid leukemia-specific cytotoxic T lymphocytes. (A) Flow cytometry assay of the phenotype of monocyte-depleted peripheral blood lymphocytes stimulated with Kasumi-3 cells pretreated with mitomycin $\mathrm{C}$ and induced to proliferate with IL-2. The Q2 zone represents $\mathrm{CD} 3{ }^{+} \mathrm{CD} 8^{+}$lymphocytes. (B) The target cell viability percentage following treatment with $\mathrm{CD} 3^{+} \mathrm{CD} 8{ }^{+}$lymphocytes at varying $\mathrm{E}: \mathrm{T}$ ratios. $\mathrm{CD}$, cluster of differentiation; E:T, effector vs. target cell.

General Hospital of PLA (Sichuan, China). A total of $2 \times 10^{5}$ Kasumi-3 cells were treated with mitomycin C (Genia Biology, Beijing, China) for $30 \mathrm{~min}$ at $37^{\circ} \mathrm{C}$ and then co-cultured with the $1 \times 10^{5}$ PBLs for 4 days. Half of the medium was discarded, and the PBLs were collected and re-added into a fresh culture with $2 \times 10^{5}$ Kasumi-3 cells for continuous stimulation. The culture medium was replaced with immune cell-specialized medium on day 3. A total of $10 \mathrm{U} / \mathrm{ml}$ human recombinant IL-2 (BioDee, Beijing, China) was added into the medium on day 3. Every 3 days, half of the medium was changed with fresh immune cell-specialized culture medium (GT-T551 medium) and the IL-2 concentration was kept at $10 \mathrm{U} / \mathrm{ml}$. The stimulation procedure was repeated every week for 3 weeks. In this system, the $\mathrm{T}$ cells that could recognize the cancer cells survived and proliferated, and the T cells that could not gradually underwent apoptosis. Immune phenotype characterization of the resulting AML-CTLs was performed using fluorescein-conjugated antibodies directed against human CD3 and CD8 (cat. no. 558261 and 560662; BD Biosciences, Franklin Lakes, NJ, USA) with a flow cytometer, according to the manufacturer's instructions and our previous study (20).

CTL cytotoxicity assay. Target cells (Kasumi-3 cells; $1 \times 10^{6}$ ) were co-cultured with 2.5, 5.0,10.0 and 20.0 CTLs concentrations of effector:target (E:T) cell ratio at cell densities of $3.5 \times 10^{6}, 6.0 \times 10^{6}, 11.0 \times 10^{6}$ and $21.0 \times 10^{6}$, respectively, per 6-well plate for $4 \mathrm{~h}$ at $37^{\circ} \mathrm{C}$. Subsequently, MTT assays were performed to evaluate cells viability. MTT solution (20 $\mu \mathrm{l}$; $5 \mathrm{mg} / \mathrm{ml}$ ) was added to the wells and the plates were incubated for $1.5 \mathrm{~h}$. The supernatant was carefully discarded and the plates were washed with PBS 3 times. Dimethylsulfoxide $(150 \mu \mathrm{l})$ was added to each well and the plates were put on shaker for 20 min until the formazan crystals dissolved 

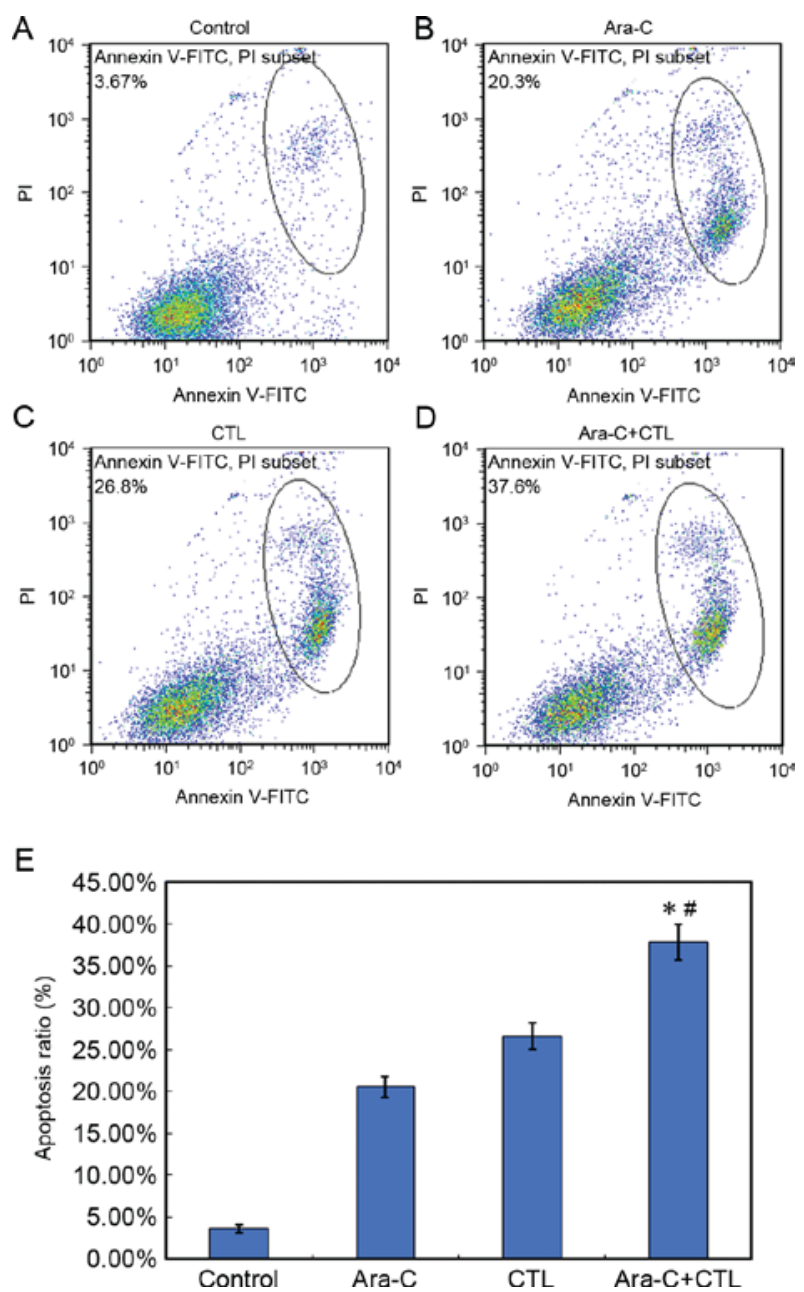

Figure 2. Ara-C-induced AML cell apoptosis is enhanced by CTL treatment. Target cells $\left(1 \times 10^{6}\right)$ were (A) untreated or treated with (B) Ara-C, (C) CTLs, or (D) Ara-C and CTLs for $4 \mathrm{~h}$ at $37^{\circ} \mathrm{C}$. (E) Apoptosis of AML cells following different treatments. ${ }^{*} \mathrm{P}<0.05$ vs. Ara- $\mathrm{C}$ treatment alone; ${ }^{\text {}} \mathrm{P}<0.05$ vs. CTL treatment alone. Ara-C, cytarabine; AML, acute myeloid leukemia; CTL, cytotoxic T lymphocyte.

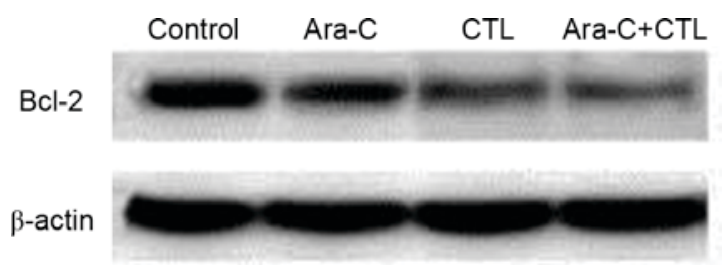

Figure 3. Ara-C and CTL combined treatment downregulates Bcl-2 protein expression in acute myeloid leukemia cells. Bcl-2 protein expression was measured by western blotting. Ara-C, cytarabine; CTL, cytotoxic T lymphocyte; Bcl-2, B-cell lymphoma 2.

completely. The absorbance of the wells at $570 \mathrm{~nm}$ was then measured using a microplate reader to determine cell viability.

Cell apoptosis assay. Target cells $\left(1 \times 10^{6}\right)$ were treated with $200 \mathrm{nM}$ cytarabine, $20 \times 10^{6} \mathrm{CTLs}$, or cytarabine and CTLs for $4 \mathrm{~h}$ at $37^{\circ} \mathrm{C}$. Untreated cells were sued as the control group. A total of $1 \times 10^{5} / 100 \mu 1$ target cells were collected. The cells were washed with PBS and then resuspended with $200 \mu 1 \mathrm{PBS}$ for flow cytometry apoptosis analysis. An Annexin V-FITC Apoptosis assay kit (BD Pharmingen, San Diego, CA, USA) was used to detect the apoptosis rate of target cells according to the manufacturer's protocol. The total number of cells to be harvested was set at $1 \times 10^{5}$ and the speed of collection was set at 200-300 cells/sec. FlowJo software (version 7.6; Tree Star, Inc., Ashland, OR, USA) was used for data analysis.

Western blotting. The cells were harvested after $4 \mathrm{~h}$ treatment with $200 \mathrm{nM}$ cytarabine, $2 \times 10^{7} \mathrm{CTLs}$, or cytarabine and CTLs at $37^{\circ} \mathrm{C}$. Untreated cells were sued as the control group. RIPA buffer was used to lyze the cells, and then all products were transferred into Eppendorf tubes for centrifugation at $4^{\circ} \mathrm{C}$ for $15 \mathrm{~min}$ at $100,000 \mathrm{x} \mathrm{g}$. The supernatant was collected and cell lysates concentration was detected using the Bradford method (21). Sample concentration was modulated to $20 \mu \mathrm{g} / 20 \mu \mathrm{l}$ and the same concentration $\beta$-actin protein was used as an internal reference. The samples were added into 2X SDS buffer solutions and boiled at $90^{\circ} \mathrm{C}$ for $5 \mathrm{~min}$. Then, $20 \mu \mathrm{l}$ samples were separated using $20 \%$ SDS-PAGE, followed by electrotransfer onto polyvinylidene difluoride membranes. The membranes were washed with TBS for $5 \mathrm{~min}$ and blocked with skimmed milk for $1 \mathrm{~h}$ at room temperature. After 3 washes with TBS/T, the membranes were incubated with the following primary antibodies: human Bcl-2 monoclonal antibody (1:1,000 dilution; cat. no. ab694; Abcam, Cambridge, UK) at $4{ }^{\circ} \mathrm{C}$ overnight and then incubated with peroxidase-conjugated Immunoglobulin $\mathrm{G}$ antibodies (1:400 dilution; cat no. 330; Medical \& Biological Laboratories Co., Ltd., Nagoya, Japan) for $1 \mathrm{~h}$ at $37^{\circ} \mathrm{C}$. The membranes were washed 3 times with TBS/T and 1 time with TBS. Protein bands were visualized using enhanced chemiluminescence and imaged with a Gel Doc ${ }^{\mathrm{TM}}$ system (Bio-Rad Laboratories, Inc., Hercules, CA, USA).

Statistical analysis. Data are presented as the means \pm standard deviation. The statistical significance of differences between groups was compared with one-way analysis of variance. SPSS software (version 16.0; SPSS, Inc., Chicago, IL, USA) was used for all statistical analyses. $\mathrm{P}<0.05$ was considered indicate a statistically significant difference.

\section{Results}

Cytotoxicity of the generated AML-specific CTLs. CTLs are an important tool in cancer immunotherapy, and the present study aimed to generate AML-specific CTLs in vitro through immune cell stimulation. The results revealed that $>80 \%$ of the cells generated from the PBL samples were $\mathrm{CD} 3^{+} \mathrm{CD} 8^{+}$, which are considered AML-specific CTLs (Fig. 1A). The $\mathrm{CD}^{+} \mathrm{CD}^{+}$ $\mathrm{T}$ cells generated displayed cytotoxicity towards Kasumi-3 AML cells. MTT assays demonstrated that the target cell viability rate differed with varying E:T ratios (Fig. 1B). The cell viability rate was $95.2 \pm 2.43 \%, 90.2 \pm 3.02 \%, 82.6 \pm 3.67 \%$ and $74.2 \pm 2.53 \%$ for E:T ratios of 2.5:1, 5.0:1, 10.0:1 and 20.0:1, respectively.

Cytarabine-induced AML cell apoptosis is enhanced by CTL treatment. Cytarabine is an effective agent for the treatment of AML, so the effect of combining CTL immunotherapy with cytarabine on AML cell apoptosis was investigated (Fig. 2). After a $4 \mathrm{~h}$ treatment with $200 \mathrm{nM}$ cytarabine, $>20 \%$ 
of Kasumi-3 AML cells underwent apoptosis. Kasumi-3 cells treated with CTLs at a ratio of 20:1 underwent apoptosis at a rate of $26.8 \pm 1.25 \%$. Notably, the combination of cytarabine and CTLs causes an AML cell apoptosis rate of $37.6 \pm 1.42 \%$. Compared with either monotreatment, cytarabine and CTL combined treatment significantly increased AML cell apoptosis $(\mathrm{P}<0.05$; Fig. 2E).

Cytarabine and CTL combined treatment downregulates Bcl-2 expression in AML cells. The underlying molecular mechanisms of the synergistic effect of cytarabine and CTL combined treatment on AML cell apoptosis were investigated. Bcl-2 is an important protein in apoptosis; therefore, $\mathrm{Bcl}-2$ expression in the AML cells was measured after cytarabine and/or CTL treatment (Fig. 3). Compared with the untreated control group, Bcl-2 expression was inhibited in the treatment groups to varying degrees. The most notable downregulation of Bcl-2 occurred in the cytarabine and CTL combined treatment group, which indicates that $\mathrm{Bcl}-2$ downregulation mediates the synergistic effect of this treatment in promoting AML cell apoptosis.

\section{Discussion}

The interactions between immune cells and chemotherapeutics have been researched in depth. Previous reports have demonstrated that docetaxel can modulate $\mathrm{CD}^{+}, \mathrm{CD}^{+}, \mathrm{CD} 19^{+}, \mathrm{NK}$ cell and T-regulatory (Treg) cell populations in non-tumor bearing mice, and enhance interferon $-\gamma$ production by $\mathrm{CD} 8^{+}$ $\mathrm{T}$ cells (22). In addition, the combination of chemotherapy and radiation for the treatment of human head and neck squamous cell carcinoma was identified to augment CTL-mediated cell lysis (23). Another report revealed that the exposure of lung tumor cells to cisplatin and vinorelbine increased sensitivity to CTL-mediated cytolysis (24). Cisplatin may induce sub-myeloablative leucopenia through modulating reconstitution of Treg vs. effector T-cell subsets, and can be employed in combination with immunotherapy to exploit the homeostatic peripheral expansion of T cells (24). The enhanced antitumor immune responses triggered by chemotherapeutics cause what is known as immunogenic cell death. These results suggest that the combination of immunotherapy with chemotherapy may improve the clinical outcomes of cancer treatment. Indeed, small numbers of CTLs can mediate potent antitumor effects when combined with chemotherapy (17). The combination of CD40 ligation immunotherapy with gemcitabine has been demonstrated to induce solid tumor reduction and reverse drug resistance (25). The activation of CD40 on cervical carcinoma cells can facilitate CTL responses and enhance chemotherapy-induced apoptosis (26). In addition, combining immunotherapy and targeted therapies could improve clinical outcomes via cross modulation (27).

Various mechanisms may explain the synergistic effect of immunotherapy and chemotherapy. The direct effects of chemotherapy on the tumor or tumor microenvironment, including induction of tumor cell death, elimination of regulatory $\mathrm{T}$ cells and enhancement of tumor cell sensitivity to lysis by CTLs may account for enhancement of immunotherapy by chemotherapy. Furthermore, the lymphopenia caused by chemotherapy has been identified to increase the efficacy of adoptive lymphocyte infusion in patients with cancer (28).
Immunotherapy may also directly regulate tumor chemosensitivity. The present study investigated the effects of combined CTL and cytarabine treatment on AML cells. The results revealed that, compared with either treatment alone, the combination of CTLs with cytarabine significantly increased AML cell apoptosis. Western blot results also indicated that the inhibition of AML cell Bcl-2 expression may be the mechanism underlying to this effect.

There are several limitations to CTLs treatment, including shortcomings in specificity and cytotoxic competence. The specific targeting of immunotherapy could improve these issues; for example, chimeric antigen receptor-modified $\mathrm{T}$ cell (CAR-T) treatment. CART-123 cells, which target the CD123 antigen on tumor cells, have achieved favorable results whereby CD123 CAR T cells exhibited antileukemic activity in vivo against a xenogeneic model of AML and significantly prolonged the models' survival (29). CAR-T treatments are able to reduce tumor burden prior to the application of alternative intensive strategies, including HSCT (30). However, due to the potent cytotoxic effects of CAR-T, serious side effects are currently associated with treatment. Whether CAR-T therapy will improve upon CTL immunotherapy remains unclear and further studies into these treatments are warranted.

In conclusion, the results of the present study demonstrated that the combination of CTL and cytarabine treatment significantly increased AML cell apoptosis, and indicated that this synergistic effect is due to the downregulation of Bcl-2. Optimizing the specificity and potency of CTLs, and identifying favorable combinations with other chemotherapeutic drug remain important tasks for future work.

\section{Acknowledgements}

The present study was supported by Cheng Du Military General Hospital Management Research Foundation (grant no. 2013YG-B045).

\section{References}

1. Rubnitz JE, Inaba H, Dahl G, Ribeiro RC, Bowman WP, Taub J, Pounds S, Razzouk BI, Lacayo NJ, Cao X, et al: Minimal residual disease-directed therapy for childhood acute myeloid leukaemia: Results of the AML02 multicentre trial. Lancet Oncol 11: 543-552, 2010.

2. Niewerth D, Creutzig U, Bierings MB and Kaspers GJ: A review on allogeneic stem cell transplantation for newly diagnosed pediatric acute myeloid leukemia. Blood 116: 2205-2214, 2010.

3. Couzin-Frankel J: Breakthrough of the year 2013. Cancer immunotherapy. Science 342: 1432-1433, 2013.

4. Greiner J, Schmitt M, Li L, Giannopoulos K, Bosch K, Schmitt A, Dohner K, Schlenk RF, Pollack JR, Dohner H and Bullinger L: Expression of tumor-associated antigens in acute myeloid leukemia: Implications for specific immunotherapeutic approaches. Blood 108: 4109-4117, 2006.

5. Castella B, Vitale C, Coscia M and Massaia M: V $\gamma 9 \mathrm{~V} \delta 2 \mathrm{~T}$ cell-based immunotherapy in hematological malignancies: From bench to bedside. Cell Mol Life Sci 68: 2419-2432, 2011.

6. Van Driessche A, Berneman ZN and Van Tendeloo VF: Active specific immunotherapy targeting the wilms' tumor protein 1 (WT1) for patients with hematological malignancies and solid tumors: Lessons from early clinical trials. Oncologist 17: 250-259, 2012.

7. Brossart P, Schneider A, Dill P, Schammann T, Grünebach F, Wirths S, Kanz L, Bühring HJ and Brugger W: The epithelial tumor antigen MUC1 is expressed in hematological malignancies and is recognized by MUC1-specific cytotoxic T-lymphocytes. Cancer Res 61: 6846-6850, 2001. 
8. Theobald M, Biggs J, Hernández J, Lustgarten J, Labadie C and Sherman LA: Tolerance to p53 by A2. 1-restricted cytotoxic T lymphocytes. J Exp Med 185: 833-841, 1997.

9. Burstein HJ and Schwartz RS: Molecular origins of cancer. N Engl J Med 358: 527, 2008.

10. Berger C, Turtle CJ, Jensen MC and Riddell SR: Adoptive transfer of virus-specific and tumor-specific T cell immunity. Curr Opin Immunol 21: 224-232, 2009.

11. Brimnes MK, Gang AO, Donia M, Thor Straten P, Svane IM and Hadrup SR: Generation of autologous tumor-specific T cells for adoptive transfer based on vaccination, in vitro restimulation and CD3/CD28 dynabead-induced T cell expansion. Cancer Immunol Immunother 61: 1221-1231, 2012.

12. Hirohashi Y, Torigoe T, Inoda S, Morita R, Kochin V and Sato N: Cytotoxic T lymphocytes: Sniping cancer stem cells. Oncoimmunology 1: 123-125, 2012.

13. Falkenburg JF, Wafelman AR, Joosten P, Smit WM, van Bergen CA, Bongaerts R, Lurvink E, van der Hoorn M, Kluck P, Landegent JE, et al: Complete remission of accelerated phase chronic myeloid leukemia by treatment with leukemia-reactive cytotoxic T lymphocytes. Blood 94: 1201-1208, 1999.

14. Yee C, Thompson J, Byrd D, Riddell SR, Roche P, Celis E and Greenberg PD: Adoptive T cell therapy using antigen-specific $\mathrm{CD} 8+\mathrm{T}$ cell clones for the treatment of patients with metastatic melanoma: In vivo persistence, migration, and antitumor effect of transferred T cells. Proc Natl Acad Sci USA 99: 16168-16173, 2002.

15. Bracci L, Schiavoni G, Sistigu A and Belardelli F: Immune-based mechanisms of cytotoxic chemotherapy: Implications for the design of novel and rationale-based combined treatments against cancer. Cell Death Differ 21: 15-25, 2014

16. Ramakrishnan R, Huang C, Cho HI, Lloyd M, Johnson J, Ren X, Altiok S, Sullivan D, Weber J, Celis E and Gabrilovich DI: Autophagy induced by conventional chemotherapy mediates tumor cell sensitivity to immunotherapy. Cancer Res 72 : 5483-5493, 2012.

17. Ramakrishnan R, Assudani D, Nagaraj S, Hunter T, Cho HI, Antonia S, Altiok S, Celis E and Gabrilovich DI: Chemotherapy enhances tumor cell susceptibility to CTL-mediated killing during cancer immunotherapy in mice. J Clin Invest 120 : 1111-1124, 2010.

18. Shurin GV, Tourkova IL, Kaneno $R$ and Shurin MR: Chemotherapeutic agents in noncytotoxic concentrations increase antigen presentation by dendritic cells via an IL-12-dependent mechanism. J Immunol 183: 137-144, 2009.

19. English D and Andersen BR: Single-step separation of red blood cells. Granulocytes and mononuclear leukocytes on discontinuous density gradients of Ficoll-Hypaque. J Immunol Methods 5 : $249-252,1974$
20. Deng R, Wang SM, Yin T, Ye TH, Shen GB, Li L, Zhao JY, Sang YX, Duan XG and Wei YQ: Inhibition of tumor growth and alteration of associated macrophage cell type by an HO-1 inhibitor in breast carcinoma-bearing mice. Oncol Res 20 473-482, 2013

21. Kruger NJ: The Bradford Method for Protein Quantitation. Methods Mol Biol 32: 9-15, 1994.

22. Garnett CT, Schlom J and Hodge JW: Combination of docetaxel and recombinant vaccine enhances $\mathrm{T}$-cell responses and antitumor activity: Effects of docetaxel on immune enhancement. Clin Cancer Res 14: 3536-3544, 2008.

23. Gelbard A, Garnett CT, Abrams SI, Patel V, Gutkind JS, Palena C, Tsang KY, Schlom J and Hodge JW: Combination chemotherapy and radiation of human squamous cell carcinoma of the head and neck augments CTL-mediated lysis. Clin Cancer Res 12: 1897-1905, 2006.

24. Gameiro SR, Caballero JA, Higgins JP, Apelian D and Hodge JW: Exploitation of differential homeostatic proliferation of T-cell subsets following chemotherapy to enhance the efficacy of vaccine-mediated antitumor responses. Cancer Immunol Immunother 60: 1227-1242, 2011.

25. Nowak AK, Robinson BW and Lake RA: Synergy between chemotherapy and immunotherapy in the treatment of established murine solid tumors. Cancer Res 63: 4490-4496, 2003.

26. Hill SC, Youde SJ, Man S, Teale GR, Baxendale AJ, Hislop A, Davies CC, Luesley DM, Blom AM, Rickinson AB, et al: Activation of CD40 in cervical carcinoma cells facilitates CTL responses and augments chemotherapy-induced apoptosis. J Immunol 174: 41-50, 2005.

27. Vanneman M and Dranoff G: Combining immunotherapy and targeted therapies in cancer treatment. Nat Rev Cancer 12: 237-251, 2012.

28. Zhang T and Herlyn D: Combination of active specific immunotherapy or adoptive antibody or lymphocyte immunotherapy with chemotherapy in the treatment of cancer. Cancer Immuno Immunother 58: 475-492, 2009.

29. Mardiros A, Dos Santos C, McDonald T, Brown CE, Wang X, Budde LE, Hoffman L, Aguilar B, Chang WC, Bretzlaff W, et al: $\mathrm{T}$ cells expressing CD123-specific chimeric antigen receptors exhibit specific cytolytic effector functions and antitumor effects against human acute myeloid leukemia. Blood 122: 3138-3148, 2013.

30. Wang QS, Wang Y, Lv HY, Han QW, Fan H, Guo B, Wang LL and Han WD: Treatment of CD33-directed chimeric antigen receptor-modified T cells in one patient with relapsed and refractory acute myeloid leukemia. Mol Ther 23: 184-191, 2015. 